\title{
Ontplooiing van Godsbegrip by die skoolkind
}

\author{
Millie Olivier \\ (Departement Ortopedagogiek Pretoria)
}

\section{Inieiding}

Die moontlikheid tot Godsbegrip is met menswees gegewe. Die ontluiking en ontplooiing van hierdie moontlikheid tot werklikheid vind ook inderdaad plaas lank voordat dit kind skoolgaande ouderdom bereik. Weens die feit dat die voorskoolse kind se verstandsmoontlikhede egter nog ongedifferensieerd is, sy ervaringsbesit skraal in omvang en infantiel van aard is en bowe-al die feit dat taalverwerwing nog nie genoegsame momentum aangeneem het nie, is die kleuter inderdaad nog nie gereed vir formele kategese in georganiseerde kerkverband nie.

Waar die saak van formele kategese tans opnuut aandag geniet hier te lande en in die Nederduitsch Hervormde Kerk van Afrika in die besonder, is dit raadsaam om die bevatlikheid van die kind as katkisant van nader te beskou.

Kinderlike wording na al sy fasette en in sy ryklik geskakeerde verskyningsvorme is reeds indringend bestudeer. Een van die wyses van menswees waarin die kind in ons midde sig aan ons openbaar, naamlik sy moontlikheid tot Godsbegrip is egter nog relatief minder bekend.

In 'n poging tot ordening van die komplekse verskynsel word 'n indeling gevolg wat berus op kronologiese ouderdom. Daar moet egter steeds onthou word dat elke kind uniek en onherhaalbaar is, daar bestaan groot indiwiduele en geslagsverskille tussen kinders en kultuurverskille moet in berekening gebring word. Ouderdom kan ten beste slegs ' $n$ vae aanduiding van grense wees.

Met inagneming van al die besware teen en tekortkominge van 'n faseologiese indeling van kinderlike wording, blyk dit steeds van groot praktiese waarde te wees. Die sin van teoretisering aangaande kategese is onder andere geleë in verryking van die praktyk. Die volgende indeling word dus aan die hand gedoen.

\section{DIE KLEINKINDERFASE (5 tot 7 jaar)}

Tydens hierdie lewensfase is die kind se Godsbegrip ten nouste verweef met sy begrip van ouerskap. Klink $(5,27)$ stel dit selfs nog 
sterker: "In religious terms, the experience of father and mother is a condition of faith." Ook die befaamde Nederlandse pedagoog M J Langeveld beaam die feit dat vader en moeder van wie die jong kind totaal afhanklik is, God vir hom verteenwoordig.

Geleidelik besef die kind dat sy vader en moeder aan besliste perke onderworpe is. Hulle is nie almagtig nie, het nie alle kennis in pag nie, is nie alomteenwoordig nie en is ook nie onbeperk tot sy beskikking nie. Hierdie insig is nodig alvorens ' $n$ kind tot outentieke Godsbegrip kan kom $(2,79)$. Die kind kom tot die besef dat God anders is as sy ouers. Hierdie besef kan eers posvat wanneer die kind dermate ge-emansipeer het, dat hy hom van sy ouers kan distansieer en selfstandig kan eksploreer.

Op kognitiewe vlak is die kind nog grootliks konkreet gebonde in sy denke. Hy kan nog nie op abstrakte niveau 'n gevolgtrekking maak nie. Gevolglik kan hy nie 'n redenasie volg wat op afleiding gebaseer is nie. Hy kan nie veralgemeen nie. Geisoleerde feite vorm die basis van sy besluite.

Die klein kind is grootliks egosentries. Net aangeleenthede, sake of dinge wat direk op hom betrekking het, het vir hom positiewe $\sin$.

Hy het nog nie insig in oorsaak en gevolg nie. Hy leef hier en nou. Net dit wat op die onmiddellike betrekking het, is vir hom waardevol. Die kind se tydsbegrip is nog baie difuus. Nou is vir hom belangrik. Netnou kan net so wel môre of volgende jaar gewees het, dit is om't ewe. Hy kan nie die plesier van die oomblik uitstel ter wille van 'n groter gewin in die toekoms nie. Om vir hom Vrydag sy teks te begin leer sodat hy dit Sondag sal ken, is om hom Vrydag te laat besluit: "teksleer is nie lekker nie". Die 5 tot 7 jarige beken die wêreld via sy gevoel. Wat lekker is, is goed, wat sleg is, is verkeerd en vermy hy. Dit dien geen doel om vir hom te vra na 'n rede nie. Hy kan nog nie die situasie rasioneel verklaar nie en antwoord eenvoudig: "sommer!"

Die skeidslyne tussen die werklikheid en fantasie is vaag. Wat hy nie vir seker weet nie, vul hy aan uit sy verbeelding. Vele van die fantasieleuens wat die jong kind vertel, berus op wensdenkery. Hy vertel vir jou wat hy dink dat jy graag wil hoor ter wille van 'n aangename gevoelsklimaat en om goedkeuring te ontlok. Daar is nog ' $n$ intense besef van afhanklikheid van die volwassene.

Hierdie afhanklikheidsgevoel van 'n beskermde volwassene bring mee dat "the child moves from deifying his parents to parentalising the deity" aldus Goldman (2, 79-80). Die begrip van die Vaderskap van God is dus een wat hy geredelik aanvaar. ' $n$ Vader beteken vir hom iemand met krag, sterkte, gesag, mag en leierskap. 'n Moeder is iemand wat vertroetel, en is ' $n$ bron van liefde, deernis en vertroos- 
ting. In die lig hiervan neem die gebed van 'n vyfjarige wat gebid het: "In the name of the father and the mother, Amen" nuwe betekenis aan.

Alle inligting aangaande God word geïnterpreteer in terme van die kind se eie partikuliere ervaringsbesit. So het 'n vyfjarige per geleentheid vir my gevra: "Maar sal Hy ooit kan hoor as ons dan so saggies bid?" en 'n sewejarige: "Is he a bulb that never switches off?" (n.a.v. 'n Engelse lied oor 'n "ever shining light"). Dink net watter ryk bron van verwarring is ons eie berymde psalms en gesange!

Die kind aanvaar blindelings alles wat vir hom gesê word, mits dit kom van ' $n$ persoon wat hy vertrou en ken en indien hy beleef dat hy in liefde aanvaar word. Daar is egter nog geen sprake van 'n outentieke Godsbegrip nie.

Ek moes per geleentheid vir 'n groep Engelse 6 en 7 jariges die Onse Vader leer. Maandagoggend in die saal bid almal toe plegtig saam:

"Our Father which art a lemon

Hallo be Thy name ...... deliver

us from all eagles ......."

Die kind tussen 5 en 7 het nood aan sekuriteit. Skooltoetrede bring 'n groot omwenteling teweeg in die lewe van die jong kind. Dit bring vele nuwe uitdagings, aanpassings, opwinding, maar ook spanning en onsekerheid.

' $n$ Vaste roetine dra by tot ' $n$ gevoel van veiligheid. Die 5 tot 7 jarige is besonder afhanklik van ' $n$ intieme persoonlike verhouding met ' $n$ steungewende volwassene. In nood het hy gerusstelling, aanmoediging en vertroeteling nodig. Kategete stig dikwels verhouding met die kinders as ' $n$ groep. Die kind identifiseer egter nog nie met die groep nie en hunker na 'n verhouding tussen hom as enkeling en die volwassene.

Die 5 en 7 jarige is nog nie gereed vir kategetiese taal nie. Woorde soos heilig, salig, ewig, toevlug, vergifnis, ontferm, barmhartig, berou, sonde, sabbat, offer, naaste, ensovoorts kan nie anders as om hierdie kind met sy beperkte ervaringsbesit te verwar nie.

Kognitiewe verwarring wek gevoelsonrus. Wanneer hierdie verwarring stelselmatig week vir week herhaal word, vind dit neerslag in negatiewe singewing. Die kind wys die gebeure af en onttrek.

Wat die klein kind nodig het, is nie soseer inskakeling by formele kategese nie, maar 'n toereikende opvoedingsverhouding met ' $n$ gelowige ouer. Klink $(5,15)$ sê: "Faith never comes about on its own. It must be aroused", en verder aan "The faith of parents is contagious without them ever consciously speaking about it" $(5,28)$. Die 
kennis, insig, begrip, waardering en gevoelsekerheid wat die jong kind op so 'n wyse bekom, vorm 'n skat van voorkennis waarop die kategeet later kan bou.

\section{DIE MIDDELKINDERJARE (8 tot 10 jaar)}

Die kind is nog tot 'n groot mate konkreet gebonde in sy denke, maar begin nou veralgemeen. Vroeër het hy geweet dis verkeerd om 'n maatjie se lekkers te vat, nou weet hy dis verkeerd om te steel (4, 409). Daar is by hom 'n bewuswees van algemeen geldende norme, reëls en gedragskodes. Hy begin insien daar is ' $n$ regte manier van doen en 'n verkeerde. Hy aanvaar die waardes en norme wat sy opvoeders aan hom voorhou, onkrities. Die meriete word nie bevraagteken nie.

Hy is nog egosentries in die sin dat hy alles in direkte verband bring met homself, maar daar is ' $n$ groot bewuswording van die medemens. In medemenslike verhoudinge is hy egter nog onbeholpe en veral takt is iets wat hy nie ken nie. Hy beoordeel sy medemens soos ander aspekte van die werklikheid in absolute terme: Fynere nuanses en skakeringe gaan hom verby. lets is ò goed òf dit is sleg, dis reg of verkeerd.

Sy gevoelslewe is nie meer aan soveel fluktuasies onderworpe nie en hy begin oefen aan selfbeheersing, mits dit aan hom voorgehou word as ' $n$ deug. Hy raak nie meer sodanig meegevoer deur'n treurige verhaal dat hy in trane uitbars nie, inteendeel bloedige $\mathrm{Ou}$ Testamentiese oorloë en gepaardgaande heldedade val reg in sy smaak.

Wat sy belangstelling betref, is hy ' $n$ realiteitsfanatikus. Alles in sy fisiese omgewing spreek hom aan. Dinge wat hy sintuiglik kan waarneem, wek sy verwondering. Feetjies en kabouters is iets van die verlede. Oor "engeltjies" is hy nog nie so seker nie. Hy interpreteer die Bybel letterlik en gevolglik meen meeste kinders van hierdie ouderdom engele is mense met vlerke.

Hierdie is ' $n$ gunstige lewensfase om die kind te laat kennis maak met die argeologiese fondse van die Bybeltydperk, die geografie, kleredrag, gebruiksartikels en sosiale gewoontes wat as nuttige agtergrond kan dien wanneer hy later met Bybelverhale kennis maak.

Fisies is die kind robuust. Hy het sy liggaam goed onder beheer, spierbewegings is goed gekoördineer en hy is ' $n$ bondel energie. Nie net is hy self besonder aktief nie, maar verlustig hom in die aktiwiteite van ander wat met fisiese daad en krag die wêreld betree.

Die 8 tot 10 jarige het reeds begrip verwerf ten aansien van oorsaak en gevolg en het 'n elementêre historiese sin. Die kind is dus gereed vir 'n kronologiese ordening van inhoud. Hy is egter nog 
steeds nie gereed vir beeldspraak en suggestie nie. Word hy geleer dat die mens nie van brood alleen kan lewe nie, dink hy daar moes seker iets te drinke by gewees het.

Hierdie aangeleentheid het besondere relevansie vir die keuse van die kategetiese inhoud, maar ook vir die taal waarin die onderrig gegee word. Dit is nou die aangewese tyd om agtergrondskennis te verskaf ten aansien van vele van die simbole wat in die Bybel gebruik word, byvoorbeeld die lam, skaap, herder, lamp, beker, wingerd, wyn, brood ensovoorts.

Ten aansien van die Godsbegrip van die 8 tot 10 jarige sê Goldman $(2,104)$ : "God is still seen as a touchy, impredictable, powerful and angry adult, often vindictive and harsh in his treatment of naughty people. At other times he is kind and loving, but always to be feared ...."

Die kind bid nou geredelik selfstandig en Jesus figureer prominent in sy gebede. Hy het egter nog geen definitiewe identiteit nie en hy vind dit moeilik om te begryp dat Hy mens was, maar tegelyk ook God is.

Die grense van sy wêreld het egter nou so verbreed dat hy bewus is van veel meer gevare, slaggate en uitdagings as voorheen. Hy het nog nood aan gerusstelling, kalmte, liefde en 'n gevoel van veiligheid. Die kind is wel deeglik bewus van die beperkinge van die volwassenes van wie hy afhanklik is en hunker na beskerming, beveiliging en liefde vanuit ' $n$ groter bron. Dit is 'n gunstige geleentheid vir die tuisbring van die almagtigheid, barmhartigheid en liefde van God.

Hierdie lewensekerheid kan nog nie vir hom deur formele onderrig toeganklik gemaak word nie. Daarvoor is sy kognitiewe ontplooiing, lewenservaring en taalverwerwing nog ontoereikend. Die voorleef van geloofsvertroue eerder as die verwoording daarvan is steeds belangrik.

Die kind is nog besonder geheg aan sy ouers en huisgesin, maar wil graag ook buite die huis lid van 'n groep wees. Hy is trots op sy skool, sy klas en sy speelgroep. Dis 'n wyse kategeet wat die geleentheid benut om die kind te laat tuisvoel in sy kerk en sy gemeente.

Die 8 tot 10 jarige is nie meer so roetinegebonde soos voorheen nie, maar hy is aangewese op vaste reëls, regulasies en gedragskodes. Hy vra om konsekwente gesagsuitoefening. Dit laat hom veilig voel en dui vir hom die grense aan waarbinne hy met veiligheid kan beweeg. 


\section{LAAT KINDERJARE (11 tot 13 jaar)}

Op 'n kognitiewe niveau kan die kind nou analiseer, klassifiseer en sinsamehange aantoon. ( $\mathrm{Hy}$ is ook ' $\mathrm{n}$ ywerige versamelaar en nie meer die ordelose gaarder van voorheen nie.) Sy ervaringsbesit neem met rasse skrede toe, danksy sy taal en veral leesvaardigheid. Koerante, ensiklopedieë, die radio en ander massamedia is vir hom toeganklik. Sy benadering tot kennisversameling is ewe-eens ' $n$ soeke na reëlmaat en sisteem. Hy benodig 'n kategeet wat didakties goed onderlê is ten einde die orde en wetmatigheid van God se skepping en sy instandhouding daarvan vir hom oop te vlek. Hy is nou gereed vir die begrip: God was gister en vandag dieselfde en is getrou tot in ewigheid.

Gevoelsmatig is die kind betreklik stabiel. Die onveiligheid en onsekerheid van die jonger kind is oorbrug en die wroeginge van die tienerjare lê nog voor.

In sy verhoudinge is hy nog net so vrymoedig en entoesiasties as voorheen. Goedkeuring en aanvaarding deur die groep is van kardinale belang. Reg, is dit wat deur die groep as reg beskou word - die mening van volwassenes kom tweede. Dit is eers teen die einde van hierdie fase dat kritiese denke na vore kom.

Teen die einde van hierdie fase begin indiwiduele verskille tussen die kinders al groter word. Dit is onder andere te wyte aan verskille in tempo van fisiese pubertering. Dogters se wording verloop teen 'n baie sneller tempo as die van seuns. Veral dogters vertoon groot onderlinge verskille. Sommiges is regte klein rabbedoes, terwyl ander meer verfynd en vroulik is, maar onderhewig aan giggelbuie. Sommige kinders toon hulself reeds gereed vir abstrakte begrippe en raak verveeld met konkreethede, terwyl hul maats van dieselfde ouderdom nog hoeganaamd nie gereed is vir outentieke geloofsleer nie.

Die kind se Godsbegrip is nou gestroop van meeste van die fantasieë van vroeër. Hierdie is egter 'n periode van kognitiewe verwarring aangaande geloofsaangeleenthede. Byvoorbeeld die kind sien in dat as God alomteenwoordig is, Hy nie aan fisiese beperkinge onderhewig kan wees nie. Vele knelvrae doen hulself voor. Die kind wonder: As God nie soos ' $n$ mens is nie, hoe is Hy dan? Hoe kan hy een, maar tegelyk drie wees? Hoe rym die wetenskap met die Bybel? Hoe kan al die diere in die ark gekom het? Is die verhaal van Jona waar? ensovoorts.

Tot dusver het hulle aan God gedink as iemand wat in die ou tyd in ' $n$ veraf land gewoon het en wat op een of ander wyse iets te doen het met Sondag, die dominee en die kerkgebou. Meteens is dit ' $n$ knelpunt om uit te maak hoe skakel daardie veraf dinge met nou en hier en hoe figureer God in die alledaagse lewe. Wat het die lewens- 
verhale van daardie ou afgestorwenes in 'n ou Israelitiese kultuur te sê vir'n moderne kind in die tegnologiese eeu? Wat is die relevansie vir die kind as indiwidu?

Die kind verwerf nou insig in die feit dat verskillende outeurs meegewerk het aan die Bybel en dat alles nie meer letterlik vertolk kan word nie. Hy het baie duidelike hulp en riglyne nodig ten einde dat die twyfel sal verminder en die geloofsekerheid sal toeneem.

Die kind identifiseer nie meer slegs die bestaan van waardes en norme nie, maar begin homself daarmee vereenselwig. Sy gebede wentel ook dikwels om die begeerte om 'n "beter" mens te wees, die welsyn van ander, of oor ' $n$ saak. Ten aansien van norme is daar nou groter stabiliteit. Hy raak nie meer verwar deur fluktuerende omstandighede nie. Skuldbesef is egter nog steeds gekoppel aan spesifieke oortredinge. Hy aanvaar nie sy sondige aard nie. Die werklike betekenis van die versoeningsdood gaan nog aan hom verby. Hy dink nog steeds aan God as regter eerder as ' $n$ God van liefde.

Ook ten aansien van die duiwel huldig die kind nou minder fantasiebeelde. Hy word beskou as die krag onderliggend aan alles wat sleg is in die wêreld - hy self as kind is egter nie daarby betrokke nie. Die duiwel staan net in verband met "groot sondes", soos moord, roof, oorloë, ensovoorts.

Ten spyte van die feit dat die mening van die portuurgroep soveel gewig dra, het die kind nog steeds nood aan leiding deur'n simpatieke volwassene.

Die kind is nou gereed vir simboliek. Bybelse simbole soos die lig, die Woord en die wingerdstok kan gebruik word om verband aan te toon tussen daardie veraf tyd en nou. Kennis van kerkgeskiedenis help die kind om die brug te slaan tussen bekende Bybelinhoude en sy alledaagse lewe. Hy is nou gereed om in te sien dat God self sy kerk in stand gehou het deur die eeue heen en dat hy, die kind 'n deel uitmaak van die kerk van vandag. "At previous stages the child happily kept together unrelated and often contradicting ideas, but now he is becoming aware of the need to relate and reconcile these apparent contradictions. We require an intensive effort in teaching religion at this stage to help him grow a 'one-word' view of life, rather than a dualistic system which separates religion from the rest of life" $(2,138)$.

Daar moet steeds in gedagte gehou word dat geloof 'n uiters personale aangeleentheid is. Dit is iets wat elke indiwidu op eie unieke wyse ervaar. Die kind is nou gereed om hierdie ervaring te verwoord. Dit is dikwels vir die kategeet makliker om vir die duur van die kategese periode self alleen die woord te voer. Die lewensfase 11 tot 13 is egter die ideale tydperk vir die hou van groepsbe- 
sprekings. Die kind is nog spontaan en entoesiasties en gaan nog nie soseer gebuk onder die selfbewustheid van die puber nie. Nou kan die indiwiduele kind daartoe gestem word om self te dink, te doen, te formuleer en te waag en ' $n$ eie mening te lug. Dit spreek vanself dat die kategesegroep klein genoeg moet wees om hierdie onderrigwyse moontlik te maak, en dat die kategete didakties onderlê moet wees om te verhoed dat die kategeseperiode in 'n algemene geklets ontaard.

Vele outeurs beskou die pre-pubertyd (dit wil sê 'n kort fase voor die aanvang van puberteit ongeveer $121 / 2$ tot $13 \frac{1}{2}$ jaar) as die waterskeiding ten aansien van geloofslewe. Aangesien die kind in hierdie fase krities is, word uitgediende ou konsepte en begrippe afgeskud en soek hy na nuwe insig en 'n meer sinvolle greep op die werklikheid.

Dit is noodsaaklik dat hy met die grootste geduld, simpatie en deernis benader word. Word die kind tydens hierdie tydperk vervreem, is dit hoogs onwaarskynlik dat hy as tiener met sy knellende lewensprobleem sy toevlug na die kerk sal neem.

\section{PUBERTEIT ( \pm 14 tot 17 jaar)}

Die kinders is nou in staat tot 'n gedistansieerde kognitiewe stellingname. In hul denke is hulle nie meer gebonde aan die konkrete of selfs die skematiese nie. Hulle kan met gemak antisipeer, redeneer, logiese gevolgtrekkings maak, analiseer en sintetiseer op abstrakte niveau. Hulle hanteer ook met toenemende gemak simbole, vergelykings en suggesties. Alles hoef nie meer met jota en tittel uitgespel te word nie; inteendeel, hulle raak maklik verveeld met oorvereenvoudiging.

Die kind is nou in ' $n$ lewensfase waar hy fisies vinnig verander. Heel dikwels voel sy liggaam vir homself vreemd. Afgesien van geslagtelike ryping wat onder meer die verskyning van sekondêre geslagskenmerke teweeg bring, is daar endokrinologiese verandering. Al hierdie veranderinge bring mee dat die puber selfs in sy fisiese bewegings onseker voel. Hy ken homself nie, maar verwag dat ander hom moet ken en begryp. Hy is sensitief vir enige verwysing na sy persoon en is tog al te bang ander sal dink hy is 'n swaap. Self voel hy egter heel dikwels wel soos 'n swaap.

Die tiener is dan ook hiper-krities. Onderwysers en ouers is "outyds" of "vertraag", maats is "eenvoudig" en enige opgaaf wat hom laat onseker voel, is "simpel en kinderagtig". Die tiener vra eindelose geduld, verdraagsaamheid, lankmoedigheid en begrip - almal persoonsmoontlikhede wat hy self nie te oorvloediglik openbaar nie. 'n Pluspunt is die feit dat hy nou 'n redelike humorsin openbaar. Dit 
is 'n wyse kategeet wat hierdie attribuut uitbuit in die wek van 'n vertrouensverhouding.

Die tiener kom baie maklik in opstand teen outoritêre gesag. Ongelukkig is dit so dat meeste opvoeders veel strenger en minder verdraagsaam is met ' $n$ sestienjarige as met ' $n$ sesjarige. Meermale is dit die gevolg van die feit dat die opvoeder self onseker voel oor sy vermoë om met hierdie kinders te kan werk, dat hy besef hulle aanvaar nie meer onvoorwaardelik sy gesag en uitsprake nie en dat hulle inderdaad besig is om te emansipeer tot eie volwassenheid. Wie met ' $n$ tiener streng en outoritêr te werk gaan, verloor hom. Hy mag wel ter wille van die vrede die skyn van gesagsaanvaarding handhaaf, maar hy verwerp die outokraat as persoon op grond van 'n gebrek aan wedersydse vertroue en daarmee verwerp hy ook sy gesag. Sonder gesag (wat 'n opvoedingsessensie is), verval alle moontlikheid van onderrig. Die doel van alle dissipline is tog dat dit sal uitloop op selfdissipline.

Die tiener wil self kies en self besluit, maar kan nog nie volledig die gevolge van sy dade dra nie. Dit is die taak van die opvoeder om saam met hom alternatiewe te verken en die konsekwensies en meriete te bepaal. Die stand van sy ervaring, taalvaardigheid, denke en kennis van geldende norme is nou sodanig dat dit moontlik is om na gespreksvoering en oorweging die kind groter keusemoontlikheid te gun. Hy wil graag voel die volwassene ag hom menswaardig en erken sy eie aandeel aan sy wording. Dit stel dan besondere eise aan die kategeet. Wie met tieners werk, moet bereid wees tot outentieke kommunikasie. Die kategeet moet van homself kan gee en bereid wees om homself kenbaar te stel. Hy wat agter die inhoud skuil en die kinders met 'n ysterhand regeer, wek rebelle (rebelsheid lê buitendien vlak onder die oppervlak!).

Daar is by die tiener 'n soeke na identiteit gekoppel aan 'n soeke na die sin van die lewe. Hulle is begaan oor aangeleenthede soos: Wie is ek? Wat gaan van my word? Maak dit regtig saak dat ek lewe? Hoe weet ek dat God bestaan? Die ongeloof van vele volwassenes in die samelewing gaan nie aan die kind verby nie. Vroeër het hy aangeneem alle volwassenes is gelowig bloot omdat sy ouers gelowig is. As tiener weet hy van beter. Nie alle tieners het die moed om hierdie vrae te verbaliseer nie. Hulle is bevrees ander sal vir hulle lag of nog veel erger, dink hulle is "kinderagtig".

Tydsbegrip veral ten aansien van kronologie is nou dermate gevestig dat die geskiedenis van die kerk en Bybel met vrug aangepak kan word. Bowe-al wil die tiener nie weer dieselfde inhoud herhaal wat hy as jonger kind behandel het nie.

Wedersydse vertroue en begrip tussen kategeet en kind is dus 'n voorvereiste. Alleen wanneer die kind veilig, aanvaar en geborge 
voel, sal hy waag om te eksploreer. In die woorde van M J Langeveld $(8,19)$ : "De kinderlijke levensvorm is onder andere gekenmerk door het grondfeit dat het kind alleen in een veilige wereld leven kan en de hem ingeschapen mogelijkheden ten goede kan verwezenlijken." Dit geld nie slegs die tiener nie, maar inderdaad kinders van alle ouderdomme.

\section{SLOTBESKOUINGE}

In hierdie sketsmatige oorsig is daar telkens gepoog om die mees ooglopende kenmerke van 'n spesifieke lewensfase wat relevansie het vir kategese, uit te lig. Dit moet egter beklemtoon word dat God in sy alwysheid elke kind as unieke indiwidu geskape het. Elke indiwiduele kind is eenmalig, onherhaalbaar en anders in sy verskyningswyse. Daar is veel meer verskille as ooreenkomste tussen kinders. Gevolglik bestaan daar nie so iets soos 'n "tipiese" kind nie.

Daar moet steeds in gedagte gehou word dat geen kind as 'n tabula rasa of blanke vel gebore word waarop die kategeet na goeddunke kan skryf nie. Die kind het 'n eie unieke, aangebore aard en persoonsmoontlikhede. Hierdie moontlikhede kan slegs binne opvoedingsverband tot werklikhede omskep word, maar hier het die kind self ' $n$ eie aandeel. Hy as mens het keusemoontlikheid, hy is inisiatief van verhoudinge, hy is nie ' $n$ speelbal in die hand van volwassenes nie.

Geen twee kinders gee op presies dieselfde wyse sin en betekenis aan die werklikheid nie. Selfs hul fisiese ontwikkeling verloop nie gelykmatig nie. Hul eie betekening van liggaamlikheid en gesitueerdheid verskil. Weens al hierdie verskille bly bogenoemde indeling slegs ' $n$ vae aanduiding van wat tydens elke leeftydsfase te wagte kan wees.

\section{Bibliografie}

1 Elkind, D A: Sympathetic understanding of the child six to sixteen. Allyn and Bacon, Boston, 1978.

2 Goldman, R: Readiness for religion; a basis for developmental religious education. Routledge and Kegan Paul, London, 1969.

3 Höll, P O: Lesvoorbereiding in Godsdiensonderrig as didakties-pedagogiese opgaaf aan die onderwyser in die laerskool. MEd verhandeling. Universiteit van Suid-Afrika, 1974.

4 Hurlock, E B: Child development. McGraw-Hill Book Company, Inc. New York, 1956. Derde druk.

5 Klink, J L: Your child and religion. Vertaal deur R A Wilson. S. C. M.London, 1972.

6 Landman, W A: Leesboek vir die Christen Opvoeder. N G Kerkboekhandel, Posbus 245, Pretoria, 1972. 
7 Landman, W A: Kind en godsdiens. N G Kerkboekhandel, Pretoria, 1975.

8 Langeveld, $M$ J: Kind en religie; enige vragen voorafgaande aan een godsdienstpedagogiek. Bijleveld, Utrecht, 1966. Tweede druk.

9 Müller, A: Conscience and the adolescent: a psychopedagogical investigation. Pedagogiekstudies nr. 84. Werkgemeenskap ter Bevordering van die Pedagogiek, Fakulteit Opvoedkunde, Universiteit van Pretoria, 1976. 